in terms of goods rather than in money terms. Taking account of inflation the average cost of borrowing in real terms in the U.K. over the past 32 years (1945-1976) is estimated as 2-3 p. Ioo. This also provides the best available estimate for discounting future returns, and it brings the opportunity cost rate into line with the social time preference rate often proposed for public investments.

The contrast is made between the value of improvements made in the national interest and of those made by breeders or firms. The former benefit from returns on all national commercial production of improved stocks and the returns accumulate and are recouped over many years. On the other hand breeders and firms benefit only from the extra sales of breeding stock due to their temporary marginal superiority over competitors and they are often at high risk of getting no returns. Implications to the form and amount of investment in animal improvement are discussed.

\title{
SENSITIVITY OF OVERALL ECONOMIC GAIN AND CORRELATED RESPONSES TO VARIATION IN ECONOMIC WEIGHTS IN AN AGGREGATE GENOTYPE FOR PIGS
}

\section{E. W. BRASCAMP}

Department of Animal Science, Agricultural University, Wageningen The Netherlands

For the aggregate genotype used in the Dutch national pig breeding scheme effects of variation in economic weights are studied. The effect of adoption of "false " economic weights on the economic response to index selection is small. The contribution of changes in different traits to this economic response varies considerably, however.

\section{EFFECT OF POPULATION TYPE ON THE DEFINITION OF BREEDING GOALS}

\section{O. DANELI}

Dpt. of Animal Breeding, Agricultural College, S-75o of Uppsala 7, Sweden

Using examples from sheep populations, the relative importance of male, female and slaughter traits is discussed in relation to different ways of obtaining replacement animals. Three types of population are distinguished, namely nucleus populations with self-supply of breeding animals of both sexes, subnucleus populations with self-supply of females only, and commercial populations buying all breeding animals. Nucleus populations which supply various other populations with breeding animals are also considered.

The examples given indicate that the appropriate breeding objectives need not be identical for both sexes, even if the animals selected are to be used in the same population. The way in which replacement is recruited influences the relative importance of the various traits to be considered within the same sex as well as the differences in appropriate breeding objectives for the two sexes. Certain consequences of discounting the economic expressions of different traits are also mentioned.

THE ECONOMIC VALUES OF VARIOUS TRAITS IN PIG BREEDING

\section{R. KARLSSON}

Dpt of Animal Breeding, Agricultural College, S. 75007 Uppsala, Sweden

An investigation concerning the economic influence on the production cost of various traits in pig breeding has been carried out. The terms " economic influence" or " economic value " of a trait in this work have been used to indicate the effect on the production cost per $\mathrm{kg}$ lean 